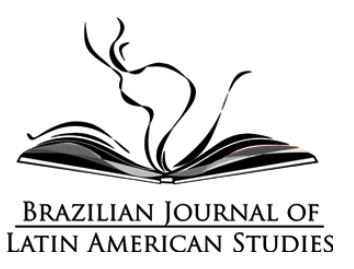

\title{
UM OLHAR SOBRE A PROTEÇÃO SOCIAL NA AMÉRICA LATINA FRENTE À PANDEMIA
}

\author{
UNA MIRADA HACIA LA PROTECCIÓN SOCIAL EN AMÉRICA LATINA \\ FRENTE A LA PANDEMIA \\ A LOOK AT SOCIAL PROTECTION IN LATIN AMERICA AGAINST THE \\ PANDEMIC
}

\author{
Adriana Aranha' (iD \\ Centro de Estudos da Metrópole/USP, Brasil \\ Carla Bronzo ${ }^{2}$ \\ Fundação João Pinheiro, Brasil
}

\begin{abstract}
Resumo: $O$ artigo parte da perspectiva de que a proteção social é um dispositivo central para o enfrentamento das desigualdades e riscos sociais, mas sua importância se amplia no contexto pós-pandemia do COVID-19, demandando uma mudança de paradigma e de novas representações e sentidos para o papel do Estado na proteção da população mais pobre e vulnerável. Partindo da descrição de tipologias de sistemas de proteção social, se analisam as respostas dadas pelos países latinoamericanos no campo da proteção não contributiva, para o enfrentamento da crise sanitária e suas implicações sociais. A partir de fontes secundárias documentos nacionais, relatórios de agências internacionais e artigos sobre o tema - o artigo propõe um balanço das iniciativas regionais de modo geral, mas com foco em oito países com alta, média e baixas brechas de proteção: Brasil, Argentina, Chile, Uruguai, Peru, Equador, Bolívia e Paraguai. Em base às informações coletadas, o artigo problematiza alguns desafios contemporâneos, no contexto da proteção social da América Latina. A conquista da cidadania, estabelecida como um desiderato nas sociedades modernas, encontra barreiras estruturais para ser efetivada na região, a mais desigual do mundo.
\end{abstract}

Palavras-Chave: Proteção social; Pandemia COVID-19; Pobreza; Desigualdade; América Latina

\footnotetext{
1 Pesquisadora Associada no Centro de Estudos da Metrópole/USP. Doutora em Administração Pública e Governo. Escola de Administração de Empresas de São Paulo da Fundação Getúlio Vargas - EAESP-FGV. E-mail: adriana.veiga.aranha@gmail.com

${ }^{2}$ Doutora em Sociologia e Política. Universidade Federal de Minas Gerais. professora e pesquisadora da Escola de Governo Fundação João Pinheiro. E-mail:carla.bronzo@fip.ma.gov.br
} 
Resumen: El artículo parte de la perspectiva de que la protección social es un dispositivo central para enfrentar las desigualdades y los riesgos sociales, pero su importancia aumenta en el contexto post pandémico de COVID-19, exigiendo un cambio de paradigma y nuevas representaciones y significados del rol del Estado en la protección a la población más pobre y vulnerable. A partir de la descripción de tipologías de sistemas de protección social, se analizan las respuestas dadas por los países latinoamericanos en el campo de la protección no contributiva, para enfrentar la crisis de salud y sus implicaciones sociales. Con base en fuentes secundarias - documentos nacionales, informes de agencias internacionales y artículos sobre el tema - el artículo propone un balance de las iniciativas de los países en general, pero con un enfoque en ocho países con brechas de protección altas, medias y bajas: Brasil, Argentina, Chile, Uruguay, Perú, Ecuador, Bolivia y Paraguay. Basados en la información recopilada para estos países, el artículo analiza algunos desafíos contemporáneos en el contexto de la protección social en América Latina. La conquista de la ciudadanía, establecida como un desiderátum en las sociedades modernas, enfrenta barreras estructurales a realizarse en la región, la más desigual del mundo.

Palabras-clave: Protección social; Pandemia COVID-19; Pobreza; Desigualdad; América Latina.

Abstract: The article starts from the perspective that social protection is a central device to face inequalities and social risks, but its importance increases in the post-pandemic context of COVID-19, demanding a paradigm shift and new representations and meanings for the role of the State in protecting the poorest and most vulnerable population. Starting from the description of typologies of social protection systems, it seeks to analyze the responses given by Latin American countries, in the field of non-contributory protection, to face the health crisis and its social implications. Based on secondary sources - national documents, reports from international agencies and articles on the subject - the article proposes a balance of the countries' initiatives in general, but with a focus on eight countries, representing countries with high, medium and low protection gaps: Brazil, Argentina, Chile, Uruguay, Peru, Ecuador, Bolivia and Paraguay. Based on the information collected for these countries, the article discusses some contemporary challenges in the context of social protection in Latin America. The conquest of citizenship, established as a desideratum in modern societies, faces structural barriers to be carried out in the region, the most unequal in the world.

Keywords: Social Protection; COVID-19 Pandemic; Poverty; Inequality; Latin America. 


\section{Introdução}

Os sistemas de proteção social podem ser definidos como mecanismos ou, mais concretamente, como um conjunto de dispositivos, políticas e programas públicos que visam garantir aos cidadãos de uma sociedade as condições para o alcance de suas necessidades básicas, que são fundamentais para sua existência, protegendo-os em relação a riscos e diversas condições de vulnerabilidade que podem vivenciar ao longo do ciclo de vida. Os sistemas variam quanto às arquiteturas de proteção, ou seja, quantos aos programas, públicos, cobertura, critérios de elegibilidade, arranjos de governança entre atores envolvidos, estruturas de incentivos e financiamentos, relações com as demais provisões realizadas pelo mercado e sociedade, dentre outras dimensões de diferenciação. Portanto, são diferentes as arquiteturas de proteção social possíveis, mais ou menos abrangentes, mais ou menos inclusivas, articulando diferentes conjuntos de políticas e com diferentes ênfases em cada uma.

Com o surgimento do vírus da COVID-19, no final de 2019, e sua expansão em 2020, os sistemas de proteção social, principalmente os não contributivos, se mostraram centrais para fazer frente aos efeitos econômicos e sociais da crise sanitária relativos ao aumento da pobreza, da fome e da desigualdade no mundo. O campo governamental sofreu o impacto da pandemia, com especial pressão para as políticas de saúde, educação e assistência social, afetando também o campo das políticas urbanas, de convivência pública, de esporte, lazer, cultura e, sobretudo, trazendo desafios não triviais para as políticas econômicas e de trabalho e renda. O crescimento da fome, da pobreza e das desigualdades na região exige ações mais robustas e sistêmicas, assim como sistemas de proteção 
social de base universal, desenhadas para fazer frente aos múltiplos vetores que contribuem para o agravamento da questão social, demandando, portanto, um Estado atuante, estratégico, orientado por concepções densas de justiça e com capacidade de financiamento para ações de inversão social.

A pandemia trouxe desafios para os sistemas de proteção por dois motivos: primeiro, a implementação operativa dos programas foi afetada, e estes tiveram que ser adaptados com urgência, como é o caso das refeições escolares em razão do fechamento das escolas, pela suspensão das aulas presenciais. Outro motivo decorre da expansão do público em condição de vulnerabilidade, causado pelo avanço do desemprego, da inatividade forçada, pressionando o sistema de proteção dos países ${ }^{3}$.

O artigo parte de uma exploração e análise das ações de proteção social não contributiva que foram produzidas para mitigar a vulnerabilidade de diferentes grupos populacionais, expostos de forma distinta aos riscos de contágio, morte ou perda da fonte de renda e emprego. Parte das tipologias construídas para caracterizar os diferentes sistemas de proteção social na América Latina e, tendo como base os dados do Observatório da Cepal, da revisão sistemática de artigos científicos e leitura de documentos produzidos pelos países e por agências internacionais, busca-se identificar as distintas ações desenvolvidas para o enfrentamento dos efeitos sociais da pandemia nos países selecionados para análise, no âmbito não contributivo. A análise concentra-se no Brasil, Argentina, Chile e Uruguai, como países que apresentam sistemas mais robustos de proteção social, tendo como contraponto as ações desenvolvidas por Bolívia e Paraguai, que são situados pelas tipologias existentes como países com sistemas de proteção social mais frágeis ou débeis. Traz ainda uma leitura sobre as ações dos países com sistemas

\footnotetext{
${ }^{3} \mathrm{Na}$ América Latina, entre 2019 e 2020, os estratos de renda média diminuíram mais de 4\%, sendo que 25 milhões de pessoas experimentaram um processo de mobilidade descendente, ainda que permanecendo nos estratos médios. Entretanto, mais de 3 milhões caíram na pobreza ou pobreza extrema. Ao contrário dos estratos médios, nos estratos de baixa renda ocorre um aumento de 4,5\%, significando um total de 28 milhões de pessoas a mais nesses estratos (CEPAL, 2021, p. 30). De acordo com a CEPAL, a estimativa é que a pobreza extrema ficou em torno de 13\%, cerca de 78 milhões de pessoas, 8 milhões a mais que em 2019; e a taxa de pobreza alcançou mais de um terço de sua população, o que totaliza cerca de 209 milhões de pessoas pobres em 2020, 22 milhões a mais do que o ano anterior (CEPAL, 2021, p. 29).
} 
considerados moderados, como Peru e Equador, para compor o grupo de países cujas ações foram examinadas.

O artigo está dividido em quatro seções, além desta introdução. Na segunda, tem-se uma contextualização sobre os sistemas de proteção social na América Latina, com a análise das tipologias utilizadas para compreender as diferentes configurações. A terceira seção recupera as ações públicas realizadas, no geral, para o conjunto dos países do continente e descreve, mais especificamente, as políticas desenvolvidas para o conjunto dos países selecionados, colocando uma lupa nas medidas adotadas, principalmente no campo das políticas de proteção social não contributivas, tais como transferência de renda e as voltadas para enfrentamento da insegurança alimentar. A quarta seção traz algumas considerações finais. $\bigcirc$ eixo de análise consiste em perceber se e como os países se utilizaram das estruturas existentes para expandir a proteção no período da pandemia; e quais os desafios mais centrais podem ser identificados nesse processo.

\section{As tipologias e o fundamento dos sistemas de proteção social na América Latina}

A discussão sobre sistemas de proteção social se conecta, diretamente, com a questão da cidadania, sendo esta compreendida em sua dimensão civil, política e social (MARSHALL, 1967) como status atribuído aos membros de uma sociedade ou, de forma mais ampliada, como "un conjunto de tensiones que se producen entre la igualdad y universalidad contenidas en el estatus formal y sus supuestos normativos, y la desigualdad material y simbólica realmente existente" (ANDRENACCI, 2019. p.1). Segundo o autor, essa tensão constitutiva entre o normativo/ideal e o realmente existente é ainda mais intensa na América Latina, cujas estruturas de desigualdade são mais antigas e persistentes. Portanto, o debate sobre proteção social, além de ser importante por demais em si 
mesmo, ganha ainda maior relevância no contexto de pós pandemia, no qual o sentido de proteção social se expande e ganha novos significados em todo o mundo, mas principalmente na América Latina, região mais desigual do planeta desde 2008 (PNUD, 2019; LUSTING, 2020). ${ }^{4}$

No século XXI, as políticas de proteção social são chamadas a responder a desafios de grande magnitude, relativos às reconfigurações das bases produtivas e tecnológicas, que impactam diretamente sobre o trabalho e sobre as condições de segurança de renda e de bem-estar social, em sociedades com ainda altos índices de pobreza e desigualdade, como as dos países latino-americanos.

Certamente as mudanças no mundo do trabalho, com o esvaziamento do trabalho formal como principal via de inserção socioeconômica e a ampliação das formas de exploração do trabalho informal, criando o que alguns autores chamam de "precariado" (ANTUNES, 2020), constituem um desafio central para a proteção social em suas dimensões contributiva e não contributiva. Para além dos desafios de pensar a proteção em um mundo no qual o trabalho formal, assalariado, não pode mais constituir-se como eixo principal da inserção social (CASTEL, 2010; ANTUNES, 2020; SUNDARARAJAN, 2019), têm-se os desafios postos pela pandemia e os reflexos sociais, econômicos e políticos da crise sanitária.

A América Latina não construiu sistemas de proteção social com a abrangência dos países desenvolvidos. Alguns países pioneiros, já na década de 1920, começaram a estruturar medidas de proteção social, e nos anos 1930 ocorreu uma alteração substantiva na arquitetura da proteção, com processos de industrialização e urbanização que demandaram atenção aos trabalhadores urbanos (RACZYNSKI, 1999, p. 174; FILGUEIRA, 1999, p. 80). Por sistemas de proteção social entende-se aqui a combinação entre três grandes componentes: a proteção social não contributiva, tradicionalmente conhecida como assistência social, que pode abranger

\footnotetext{
4 Segundo o relatório de desenvolvimento humano do PNUD, de 2019, os 10\% mais ricos da América Latina concentram uma parcela maior da renda do que qualquer outra região (37\%). E vice-versa: os $40 \%$ mais pobres recebem a menor fatia (13\%).
} 
tanto ações universais quanto focalizadas; a proteção social contributiva, ou seguridade social; e a regulação dos mercados de trabalho, que consiste em normativas e padrões que visam a proteção do trabalho decente (CECCHINI; MARTINEZ, 2011).

Na região, a emergência da proteção social vem pela via contributiva, para grupos profissionais específicos, deixando aos pobres uma assistência social marcada pelo assistencialismo. As pressões de grupos profissionais específicos pelos benefícios de proteção acabaram por gerar um modelo de proteção fragmentado, com benefícios distintos para diferentes grupos sociais, sendo a estratificação a marca do sistema. Embora reconheça que vários países implantaram programas sociais já nos anos 1920 e bem antes de outros países em desenvolvimento, Mesa-Lago (1985; 2004) considera que foi apenas no final dos anos 1970 que o modelo de seguridade emerge para a quase totalidade dos países da região.

Nos anos 1980 ocorreram reformas nos sistemas de proteção na região. A maioria dos sistemas existentes, seja na América Latina e no Caribe, ou na Europa ocidental, são constituídos por políticas que incorporam tanto elementos do seguro como da assistência social, portanto, de natureza contributiva e não contributiva (ARANHA,2019). Isto corrobora com o que foi dito por Castel (2010), que a "sociedade salarial" com proteção social universal predominante nos países capitalistas europeus foi sustentada pela combinação entre previdência contributiva, saúde universal e assistência destinada aos necessitados. Porém, como assinala Boschetti (2007), quando a predominância é do mercado informal, como nos países da América Latina e Caribe, é difícil estabelecer uma "sociedade de pleno assalariamento". Então, as relações informais e precarizadas do mercado de trabalho e o desemprego são fatores determinantes para o pouco acesso à dimensão previdenciária da proteção social.

Esta situação se agravou depois dos ajustes iniciados nas décadas de 1980 e 1990, que submeteram os países da região ao capital internacional e às orientações dos organismos internacionais como o Banco Mundial, o 
Fundo Monetário Internacional (FMI), Organização Mundial do Comércio (OMC) e diversos outros organismos da Organização das Nações Unidas (ONU). A trajetória da proteção social na região foi alterada, preconizando o Estado-Mínimo e os ajustes fiscais. Boschetti chamou esse cenário de "dilúvio neoliberal" na América Latina.

No final da década de 1980 e com mais força nos anos 1990, tem-se uma disseminação de programas de transferências condicionadas de renda (PTCR) para os pobres, com diferentes critérios de elegibilidade e valores dos benefícios, mas todos eles dirigidos às famílias consideradas como pobres ou vulneráveis a partir de algum recorte econômico e a maioria ou a quase totalidade dos programas com exigência de "contrapartidas" ou condicionalidades (BRONZO; REPETTO, 2015). Cresce, portanto, o componente não contributivo da proteção, sendo que, segundo dados de 2015, existem trinta Programas de Transferência Condicionada de Renda (PTCR) ativos em vinte países da região alcançando quase 132 milhões de beneficiários, o que representa cerca de 21\% da população regional (CECCHINI; ATUESTA, 2017, p. 21).

Os PTCR constituem uma estratégia de política pública dos sistemas não contributivos e para a análise aqui realizada é importante recuperar as tipologias construídas por vários autores, visando caracterizar e diferenciar a construção de sistemas de proteção social na região, a partir de critérios distintos (MESA-LAGO, 1985; FILGUEIRA, 1999; CECCHINI; FILGUEIRA; ROBLES, 2014)).

Não é o caso de aprofundar a discussão aqui, mas de ressaltar a perspectiva de Cecchini, Filgueira e Robles (2014), que criaram uma tipologia que cruza os estudos já existentes sobre o tema e os estudos de casos nacionais realizados pela CEPAL. Os autores observaram os gastos públicos em seguridade e assistência social, em educação e em saúde. Olharam a cobertura em pensões e também analisaram os percentuais de matrícula privada em escola primária; de gasto privado em saúde e de arrecadação tributária em relação ao Produto Interno Bruto (PIB). Diante desses dados, os autores identificaram a formação de três grupos de países 
na América Latina, cujos sistemas foram definidos como países de lacunas pequenas, de lacunas moderadas e de lacunas graves. Para identificar o tipo de lacunas ou brechas em cada país, os autores partem da compreensão de que cada país experimentou processos específicos de transição de seus mercados de trabalho, de suas taxas de fecundidade e de suas estruturas etárias. Também de seus orçamentos, de suas capacidades de gasto e de suas reformas em seus sistemas de proteção social, em curso ou potenciais.

Os países de lacunas pequenas são Argentina, Brasil, Costa Rica, Chile, Panamá, Uruguai e Venezuela. Nesses países têm-se quedas acentuadas na fertilidade, presença de população mais adulta e taxas de pobreza de 15\%, com cobertura de seguridade social em mais de 60\% de pensões e acima $80 \%$ na área de saúde. No grupo de lacunas moderadas, têm-se Colômbia, Equador, México, Peru e República Dominicana. Nesses, há um mercado de trabalho mais formalizado e taxas de pobreza entre $40 \%$ e $30 \%$. A cobertura de segurança social é de $35 \%$ de pensões e de $65 \%$ de assistência médica. Finalmente, os países que apresentavam lacunas graves: Bolívia, El Salvador, Honduras, Guatemala, Nicarágua e Paraguai. Nesses, são altos os índices de fecundidade, presença de população muito jovem, poucos empregos formais, baixos salários, grande mercado informal e de subsistência. As taxas de pobreza são superiores a 45\%, em muitos casos afetam até $2 / 3$ da população e a cobertura previdenciária alcança menos de 30\% da população (CECCHINI; FILGUEIRA; ROBLES, 2014).

O que temos, a partir dessa caracterização dos tipos de sistemas de proteção na América Latina, é a identificação de distintos graus de precariedade da cobertura previdenciária de extensas populações de diversos países devido às características do mercado de trabalho, baseado em uma ampla informalidade e instabilidade laboral. Mercados de trabalho com alto grau de precarização e altas taxas de desemprego explicam a baixa cobertura previdenciária na região.

A despeito desses dados, segundo a Nota Técnica da OIT de 2020, nos 15 anos anteriores à pandemia houve melhorias significativas nos sistemas 
de proteção social nos países da América Latina. A região teve expansão dos regimes contributivos, relacionada ao crescimento dos empregos formais, e teve expansão também dos regimes não contributivos. A cobertura de proteção social contributiva aumentou de 36,6\% em 2005 para 46,8\% em 2015, em média. Para alguns países situados nas tipologias de menores brechas e com modelos mais universalistas de provisão - como a Argentina, Chile, Costa Rica, Brasil e Uruguai -, os níveis de cobertura foram superiores a 50\% de toda a população ocupada. Em 2019, essa expansão da cobertura na região começa a ter uma pequena queda, diminuindo para 46,5\% (CASALÍ, CETRÁNGOLO, PINO, 2020, p. 3).

Como avançar com um sistema de proteção social contributiva em contextos de mercados de trabalho profundamente precários? Um ponto central nessa discussão é que na América Latina os mercados de trabalho nunca alcançaram o nível de formalização comparável aos países desenvolvidos, sendo a informalidade a sua marca, com evidentes e diretos impactos na proteção social do tipo contributivo. Embora central para a discussão sobre proteção social, a dimensão contributiva da proteção não será aqui aprofundada, mas deve enfatizar-se sua importância para uma análise adequada dos desafios da proteção.

\section{As respostas à pandemia: um olhar sobre as estratégias de diferentes países}

A pandemia tem afetado de forma intensa os países da região. De acordo com dados da CEPAL, em dezembro de 2020 a América Latina concentrava $18,6 \%$ dos contágios de Covid-19, embora tivesse apenas 8,4\% da população mundial vivendo no continente. Também quase $28 \%$ das mortes pela pandemia foram dessas populações Até junho de 2021, havia mais de 1,260 milhões de pessoas mortas pela COVID-19 na região, mais de $32 \%$ do total de mortos pela pandemia no mundo. Esse dado revela a magnitude da pandemia na região, uma vez que a população da América 
Latina e Caribe é de $8,4 \%$ da população mundial e o número de mortos assume uma proporção quase 4 vezes maior (CEPAL, 2021b, p.1). Somente no Brasil, em junho de 2021, o total era de mais de 518 mil brasileiras e brasileiros mortos pela pandemia da COVID-19.

Esse imenso choque produzido pela crise sanitária atingiu os frágeis sistemas de saúde da região, com baixa institucionalidade e recursos. Para além dos efeitos diretos da pandemia, os efeitos indiretos comprometem as taxas de fecundidade e, em múltiplos aspectos, as condições de saúde das populações. Esses problemas decorrem não apenas do enfrentamento da crise sanitária, mas das restrições impostas para o controle de doenças crônicas e para as práticas de saúde preventivas, o que impacta, de forma significativa as condições de saúde da população e os sistemas de saúde dos países latino-americanos (CEPAL, 2021c, p. 21).

Os efeitos no campo da educação são igualmente relevantes. Trinta e dois países da região fecharam as escolas, com implicações para a trajetória escolar de mais de 165 milhões de estudantes. Em países com alta desigualdade no acesso à educação, a suspensão das aulas presenciais e a opção pelo ensino remoto ampliaram as brechas digitais e comprometeram, por muitos anos, a equidade no acesso à educação para o conjunto das crianças e jovens. Ainda que a maioria tenha conseguido, de alguma forma, seguir as aulas remotas com internet, TV ou rádio, o fato é que se pode verificar a existência de uma "catástrofe geracional" que pode comprometer todos os avanços recentes, ainda que tímidos, e ampliar as desigualdades (CEPAL, 2021c, p.22). Por qualquer ângulo que se veja, a pandemia ampliou ainda mais o fosso existente nas dimensões da desigualdade na região.

De acordo com a Nota Técnica da OIT (CASALI; CETRÁNGOLO; PINO 2020), embora com matizes locais, todos os governos tomaram ações de proteção social. A entrega de alimentos e cestas básicas foi a política mais recorrente, com coberturas e montantes de benefícios diferentes, adaptando os programas escolares já existentes ou criando novas alternativas de programas. Assim, por exemplo, os alimentos foram 
entregues de modo direto nos domicílios ou foram repartidos nas escolas e cantinas escolares, quando não foram fornecidos cartões alimentação. Os critérios de elegibilidade também foram diversos, ora para gestantes, ora para famílias vulneráveis, ora para pessoas com deficiências.

Em outro âmbito de apoio econômico, alguns países aumentaram ou adiantaram as prestações e benefícios já existentes; desenvolveram ações para evitar corte de serviços (água, telefone e internet) devido ao não pagamento; permitiram que os fundos acumulados de previdência pudessem ser resgatados, ou que transferências pudessem ser antecipadas (CASALI, CETRÁNGOLO, PINO 2020).

As transferências monetárias e em espécie para os grupos já atendidos foram ampliadas ou antecipadas e novos benefícios foram criados para setores não cobertos anteriormente, predominando transferências monetárias para a população em idade de trabalhar que atua no setor informal e que perdeu renda com a pandemia. Atendidos com programas novos, embora transitórios, o grupo da população em idade ativa foi o que recebeu maior atenção das políticas de proteção na região (CASALI, CETRÁNGOLO, PINO, 2020).

Importante recuperar aqui que tais iniciativas, ainda que relativamente tímidas diante da magnitude dos riscos e efeitos impostos pela pandemia, foram fundamentais para evitar um aumento maior dos níveis de pobreza e miséria na região. Dentre tais medidas, têm-se ações de transferência de renda, seguro quanto ao acesso a serviços básicos (luz, energia internet etc), garantia de alimentos e medicamentos. A estimativa é que tais ações de transferência monetária e em espécie alcançam quase 50\% da população da região (CEPAL, 2021c, p.32).

De acordo com os dados da CEPAL, os 32 países da região implementaram 263 medidas de proteção social de emergência, de natureza não contributiva, em 2020. Essas atingiram 49,4\% da população, aproximadamente 84 milhões de domicílios ou 326 milhões de pessoas. Sem essas medidas, a incidência da extrema pobreza teria atingido 15,8\% e a pobreza, 37,2\% da população. Também tais ações foram importantes para 
diminuir, um pouco, a alta do índice de Gini na região. De acordo com as projeções, se não fossem as transferências de renda, o índice de Gini seria, em 2020, 5,6\% maior do que o índice registrado em 2019. Incorporando as transferências, o índice de Gini aumentaria também em 2020, mas em apenas 2,9\% (CEPAL, 2021c, p. 29).

Outro dado que permite verificar a magnitude das ações desenvolvidas refere-se à expansão do gasto público, com crescimento na inversão de recursos dos governos centrais nas políticas sociais. Os níveis de gasto são muito heterogêneos na região, mas no geral tem-se o predomínio dos gastos com transferências monetárias e em espécie. 0 esforço de ajuste orçamentário e recursos adicionais viabilizou a cifra de 86.214 milhões de dólares em 2020, o que equivale, na média, a 78 dólares por habitante. Esse montante é quase duas vezes maior do que o gasto com transferências monetárias e pensões sociais em 2018, o que revela uma capacidade de resposta dos países diante da crise (CEPAL, 2021c, p. 33).

\section{Ações não contributivas nos países selecionados: aproximações e distanciamentos}

O primeiro caso de COVID-19 na América Latina e Caribe foi registrado no Brasil no final de fevereiro de 2020. Logo a seguir, na primeira quinzena de março, Argentina, Chile e Uruguai tiveram seus primeiros casos. Nesse mesmo período, os governos da região começaram a anunciar medidas de proteção social em reação à queda abrupta da renda dos trabalhadores e das famílias, especialmente dos mais vulneráveis, como consequência do isolamento social proposto para enfrentamento da disseminação do vírus.

Mesmo antes da emergência da crise sanitária, os países da região enfrentavam dificuldades para financiamento público, o que limitava a capacidade fiscal de resposta à pandemia (CEPAL, 2021. p 15). Novos grupos 
de pessoas, sofrendo processos de mobilidade descendente, passaram a compor o público beneficiário das transferências, impondo pressões sobre o sistema não contributivo de proteção social dos países. A contração da capacidade fiscal dos estados ocorreu, ao mesmo tempo, com uma intensa redução da atividade econômica na região.

Como pode ser observado no Quadro abaixo, todos os países da região já contavam com algum programa de transferência de renda, a maioria com condicionalidades, ainda que apresentassem distinções entre eles em termos de cobertura e magnitude das transferências. Como medida de enfrentamento dos efeitos sociais da pandemia, tem-se que os oito países considerados desenvolveram ações de transferência de renda, sendo que foram identificadas, para o conjunto desses países, 30 ações, dentre as quais 16 novas e outras 14 derivadas de programas de transferência já existentes. As novas ações estão dirigidas, sobretudo, para pessoas inseridas no setor informal, que não faziam parte do público elegível para os programas de transferência de renda, mas que passaram a precisar dos auxílios de renda no contexto da pandemia.

Quadro 1 - Medidas de Transferência de Renda ou Alimentar na Pandemia COVID-19

\begin{tabular}{|c|c|c|}
\hline País & Programas/Beneficiários & $\begin{array}{l}\text { Pré } \\
\text { existente }\end{array}$ \\
\hline \multirow[t]{2}{*}{ Brasil } & $\begin{array}{l}\text { Auxílio Emergencial - famílias com mãe solo como chefe da } \\
\text { família, ou com indivíduos cuja principal fonte de renda } \\
\text { seja o trabalho informal ou autônomo; desempregado; ou } \\
\text { microempresários. }\end{array}$ & Não \\
\hline & $\begin{array}{l}\text { Bolsa Família quando o Auxílio Emergencial era mais } \\
\text { vantajoso para famílias que recebiam Bolsa Família (14 } \\
\text { milhões), o benefício era substituído. }\end{array}$ & Sim \\
\hline \multirow[t]{6}{*}{ Argentina } & $\begin{array}{l}\text { Aposentados, pensionistas e beneficiários de pensões não } \\
\text { contributivas. }\end{array}$ & Sim \\
\hline & Beneficiários do Asignación Universal por Hijo (AUH) & Sim \\
\hline & Asignación Universal por Embarazo (AUE) & Sim \\
\hline & $\begin{array}{l}\text { Tarjeta Alimentar - pais de crianças filiadas à AUH que não } \\
\text { tenham mais de } 6 \text { anos }\end{array}$ & Sim \\
\hline & $\begin{array}{l}\text { Tarjeta Alimentar - mulheres grávidas que têm o benefício } \\
\text { AUE }\end{array}$ & Sim \\
\hline & $\begin{array}{l}\text { Ingreso Familiar de Emergencia (IFE) - famílias cujo a } \\
\text { principal fonte de renda vem do serviço doméstico, do }\end{array}$ & Não \\
\hline
\end{tabular}




\begin{tabular}{|c|c|c|}
\hline & $\begin{array}{l}\text { mercado informal, monotributista social, ou recebem } \\
\text { programas sociais. }\end{array}$ & \\
\hline \multirow[t]{3}{*}{ Chile } & $\begin{array}{l}\text { Ingreso Familiar de Emergencia (IFE) - famílias cuja fonte } \\
\text { de renda provém principalmente de fontes informais. }\end{array}$ & Não \\
\hline & $\begin{array}{l}\text { Bono Invierno - idosos que não recebem pensão ou o valor } \\
\text { recebido é baixo ou beneficiários do programa Pensión } \\
\text { Básica Solidaria }\end{array}$ & Sim \\
\hline & $\begin{array}{l}\text { Bono de Emergencia COVID-19- famílias que recebem } \\
\text { Subsídio Familiar, famílias que pertencem aos } 60 \% \text { mais } \\
\text { vulneráveis, famílias que não têm uma renda formal. }\end{array}$ & Sim \\
\hline \multirow[t]{5}{*}{ Uruguai } & $\begin{array}{l}\text { Transferência extra para beneficiários Tarjeta Uruguay } \\
\text { Social }\end{array}$ & Sim \\
\hline & $\begin{array}{l}\text { Adultos maiores de } 65 \text { anos e ainda trabalhando no setor } \\
\text { privado (auxílio-doença devido a medidas quarentenárias) }\end{array}$ & Não \\
\hline & Transferência extra para Beneficiarios del Plan Equidad & Sim \\
\hline & $\begin{array}{l}\text { Transferência para compra de alimentos para } \\
\text { trabalhadores informais e autônomos, sem outros } \\
\text { benefícios e que não possuem previdência social }\end{array}$ & Não \\
\hline & $\begin{array}{l}\text { Transferência para determinados tipos de contribuinte } \\
\text { (monotributistas sociais) }\end{array}$ & Não \\
\hline \multirow[t]{4}{*}{ Peru } & $\begin{array}{l}\text { Bono Quédate en Casa - famílias urbanas abaixo da linha } \\
\text { de pobreza, que não são beneficiários da Pensión } 65 \text { ou do } \\
\text { Juntos }\end{array}$ & Não \\
\hline & $\begin{array}{l}\text { Bono Independiente - famílias com principal fonte de } \\
\text { renda provenientes do trabalho autônomo; }\end{array}$ & Não \\
\hline & $\begin{array}{l}\text { Bono Rural - famílias rurais abaixo da linha da pobreza, que } \\
\text { são não são beneficiários da Pensión } 65 \text { ou do Juntos }\end{array}$ & Não \\
\hline & $\begin{array}{l}\text { Bono Familiar Universal - famílias em situação de pobreza e } \\
\text { extrema pobreza; beneficiários dos programas Juntos, } \\
\text { Pension } 65 \text { ou Contigo }\end{array}$ & Sim \\
\hline \multirow[t]{2}{*}{ Equador } & $\begin{array}{l}\text { Transferência para trabalhadores autônomos ou Seguro } \\
\text { Social Campesino, com renda inferior a US } \$ 400 \text { e que não } \\
\text { estão inscritos na previdência social. }\end{array}$ & Sim \\
\hline & $\begin{array}{l}\text { Transferência para pessoas não incluídas no subgrupo } \\
\text { anterior cujos rendimentos são inferiores a US } \$ 400 \text { e estão } \\
\text { abaixo da linha da pobreza }\end{array}$ & Não \\
\hline \multirow[t]{3}{*}{ Bolívia } & $\begin{array}{l}\text { Bono Familia: transferência por criança matriculada na } \\
\text { escola }\end{array}$ & Não \\
\hline & $\begin{array}{l}\text { Bono Universal: para adultos entre } 18 \text { e } 60 \text { anos que não } \\
\text { recebem outras transferências do governo }\end{array}$ & Não \\
\hline & $\begin{array}{l}\text { Canasta Familiar: para beneficiários dos Programas Renta } \\
\text { Dignidad (idosos), Juana Azurduy (mães) e Bono } \\
\text { Deficiencia (pessoas com deficiência) }\end{array}$ & Sim \\
\hline \multirow[t]{3}{*}{ Paraguai } & $\begin{array}{l}\text { Subsídio de } 25 \% \text { do salário-mínimo por } 2 \text { meses para } \\
\text { trabalhadores informais. }\end{array}$ & Não \\
\hline & $\begin{array}{l}\text { Subsídio temporário para licença médica ou suspensão de } \\
\text { contratos para trabalhadores com carteira assinada. }\end{array}$ & Não \\
\hline & $\begin{array}{l}\text { Pagamento adicional aos beneficiários do Programa } \\
\text { Tekopora }\end{array}$ & Sim \\
\hline
\end{tabular}




\begin{tabular}{|l|l|l|}
\hline & $\begin{array}{l}\text { Uma única transferência de renda para populações } \\
\text { vulneráveis do Alto Paraná. }\end{array}$ & Não \\
\cline { 2 - 4 } & $\begin{array}{l}\text { Pytyvõ 2.0 - para os trabalhadores informais em alguns } \\
\text { setores da economia, priorizando os trabalhadores que } \\
\text { residem em cidades fronteiriças. }\end{array}$ & \\
\hline
\end{tabular}

Fonte: elaboração das autoras a partir de BUSSO et al., 2020.

Ao elencar as ações nos países pertencentes à tipologia de países com lacunas consideradas leves, tem-se que no Chile, logo após a confirmação de seu primeiro caso de COVID-19, fechou suas fronteiras, declarou estado de emergência em todo seu território e introduziu o toque de recolher, barreiras sanitárias, isolamentos e quarentenas em determinadas regiões e grupos. Foram criados dois programas de transferências de renda emergenciais: Ingreso Familiar de Emergencia (IFE) e Bono de Emergencia COVID-19. Os benefícios começaram a ser pagos em abril de 2020. Inicialmente seriam para um período de três meses, mas acabaram sendo ampliados para seis parcelas e as famílias tiveram direito ao Bono de Navidad.

Em 2021, foi lançado o IFE Ampliado, com novos benefícios para apoiar mais de 7,8 milhões de pessoas afetadas pela pandemia. 0 IFE-Quarentena e IFE Transição são benefícios desenhados de forma vinculada ao cumprimento da quarentena e do isolamento social, sendo que o primeiro se aplica aos indivíduos por tempo de quarentena e o segundo, aos municípios. Outro programa lançado foi o plano Alimentos para o Chile, que entregou ao todo 5,5 milhões de cestas de alimentos e produtos de higiene às famílias de todo o país. Foram entregues cestas básicas (café da manhã e lanche) para todos os alunos que recebiam alimentação regular na escola.

O caso da Argentina foi similar. Com a confirmação do primeiro caso na Argentina, o governo decretou o isolamento social obrigatório em todo território nacional e criou o Ingreso Familiar de Emergencia (IFE). Também foi implementado o pagamento extraordinário do Asignación Universal por Hijo (AUH) e do Asignación Universal por Embarazo (AUE) equivalente ao valor de um benefício mensal, e outros benefícios foram acrescidos de 
valores adicionais, como o caso da pensão ou aposentadoria. Foram criados três programas de apoio à renda de pessoas com deficiência, assistência domiciliar, oficinas protegidas e "bancos de suprimentos" estaduais, e foi ampliado o subsídio para famílias cobertas pelo Sistema de Proteção Social em caso de morte e estendido o subsídio às famílias vulneráveis fora do sistema de proteção social, em caso de morte por COVID-19.

A distribuição da Tarjeta Alimentar foi modificada e o montante de recursos dos cartões teve aumento de 50\%, sendo destinado às famílias atendidas pelos diversos programas de transferência de renda existentes. Outra medida foi o fortalecimento do fornecimento de alimentos para os chamados Comedores e Merenderos Comunitários, basicamente espaços físicos que prestam assistência alimentar gratuita a pessoas em situação de vulnerabilidade social. O governo lançou programas para controlar preços dos produtos essenciais e de necessidades básicas, estipulou preços máximos dos alimentos da cesta básica e criou linhas de crédito para investimentos na produção e abastecimento de alimentos e insumos. Porém, não foi observado nos documentos analisados nenhuma ação para a manutenção da alimentação para os alunos atendidos pela alimentação escolar.

O Uruguai, por sua vez, duas semanas antes de se confirmar os primeiros casos de COVID-19, declarou emergência nacional, cancelou eventos públicos, fechou as fronteiras e impôs quarentena obrigatória a todos os viajantes de países com números altos da infecção. Em relação à proteção social, o Uruguai duplicou os valores dos programas de transferências de renda existentes: Tarjeta Uruguay Social (TUS) e famílias do Plano Equidade. Inicialmente se considerou uma única parcela, mas esse benefício foi estendido até 2021, atendendo a 120 mil famílias.

Ainda no caso uruguaio, também foi priorizada a entrega de cestas básicas de emergência para trabalhadores informais e outros cidadãos não abrangidos pelos programas de transferência de renda, além do aumento da quantidade de alimentos destinados aos refeitórios municipais do interior do país e das cestas distribuídas nos territórios. Foi implantado um 
cartão de débito para compra de alimentos para alunos da Universidad de la República (Comedores Universitarios) e criado um subsídio mensal para artistas nacionais que não tinham renda de seguro-desemprego, taxas ou contratos, além de transferência de subsídios sociais para determinadas contribuintes, monotributistas sociais (microempresário, microempreendedor individual). Também foram desenvolvidos programas para melhoria de acesso à internet e outros serviços de comunicação.

Por último, nesse grupo de países, tem o caso do Brasil, onde foi criado um Auxílio Emergencial, cujo pagamento teve início em abril de 2020. Já os beneficiários do programa existente, Benefício de Prestação Continuada (auxílio pecuniário a idosos e pessoas com deficiência de baixa renda), puderam antecipar parte do benefício a que eles já tinham direito.

Os beneficiários da seguridade social, com vínculo formal de trabalho, também puderam antecipar o recebimento de um abono, ao qual eles têm direito anualmente, assim como foram liberados saques em dinheiro do FGTS (Fundo de Garantia do Tempo de Serviço) em dinheiro, até um salário-mínimo por trabalhador ${ }^{5}$. Esta medida poderia beneficiar 60 milhões de trabalhadores. Também foi antecipada a primeira (prevista antes da pandemia) e a segunda (devido ao COVID-19) parcelas do $13^{\circ}$ salário para aposentados e pensionistas do Instituto Nacional do Seguro Social (INSS) em abril e maio de 2020, respectivamente.

Em relação à área alimentar, observa-se que antes da pandemia os programas de segurança alimentar implantados no Brasil, anteriores a 2016, tiveram cortes orçamentários e financeiros substanciais. Alguns programas já tinham sido encerrados pelo Governo atual, iniciado em 2020, como a implantação de Restaurantes Populares e Cisternas para abastecimento de água, para beber e plantar, na região semiárida brasileira com uma técnica alternativa que aproveita o período chuvoso. Para outros programas, como o Programa de Aquisição de Alimentos (PAA), que compra produtos da agricultura familiar, foi garantido um crédito financeiro, porém este não supriu nem o valor retirado do orçamento.

${ }^{5} \mathrm{R} \$ 1.045,00$ reais o que equivalia a 185,25 dolares $(07 / 12 / 2021)$. 
Outro exemplo é a distribuição de cestas básicas para comunidades tradicionais e indígenas, política retomada nesse contexto de pandemia em um número bem menor ao que se distribuía antes. A retomada de políticas de proteção que foram desmontadas a partir de 2016 indica a importância do acionamento de capacidades estatais instaladas. Se esses programas tivessem sido mantidos antes da pandemia, possivelmente a proteção das famílias pobres, urbanas e rurais teria sido muito maior. Uma outra questão observada foi a falta de coordenação federal do Programa Nacional de Alimentação Escolar. Os recursos foram repassados do Programa para a distribuição de alimentos às famílias dos alunos durante o período de suspensão das aulas, mas a falta de coordenação federal deixou a política dispersa, ficando a cargo de cada município ou estado a decisão de manter o programa.

Quanto aos países com lacunas moderadas de proteção, percebe-se uma heterogeneidade com aproveitamento da rede existente no caso do Peru, e uma ação muito tímida do Equador.

O governo do Peru declarou Estado de Emergência Sanitária em 11 de março por noventa dias. No mesmo mês, foi pago 35\% do salário dos trabalhadores que ganhavam menos de 435 dólares. Ainda, foi liberado um subsídio monetário de 110 dólares (380 soles) para beneficiários em condição de pobreza ou pobreza extrema e que se encontravam em regiões com maior vulnerabilidade sanitária.

Também em março, foram adiantados três meses de transferência de renda para os beneficiários dos programas Pensión 65 e Pensão não Contributiva a Pessoas com Severa Incapacidade em Situação de Pobreza. Foi autorizado o subsídio de incapacidade temporária a trabalhadores diagnosticados com COVID-19 e foi liberada a transferência de renda para 800 mil famílias de trabalhadores informais. Um mês depois, foi liberada uma renda adicional de 760 Soles (220 dólares) para mais de um milhão de famílias rurais e repassada uma transferência de similar para 6,6 milhões de famílias sem renda, chamada de "Bono Familiar Universal". Em junho do mesmo ano, foram incluídos os trabalhadores que ganhavam menos de 
2.400 soles (695 dólares) e trabalhavam em empresas com menos de 100 pessoas, que viram sua atividade econômica cessar completamente. Para este segmento, foi repassado um recurso mensal de 760 soles (220 dólares) durante 3 meses. Em agosto de 2020, o governo criou uma nova transferência universal para 8,6 milhões de famílias. E, em fevereiro de 2021, criou-se um subsídio para famílias pobres que vivem em regiões com taxa de contágio por COVID-19 extrema. Em relação à garantia de alimentação, foram distribuídas cestas de alimentos para a população vulnerável e entregues alimentos a 3 milhões de alunos por meio do programa Qali Warma.

Já o governo do Equador realizou transferências de dinheiro entre abril e maio de 2020 para aqueles que ganhavam menos de US $\$ 400$ por mês. Foram 400 mil famílias beneficiadas. Ademais, o governo equatoriano entregou alimentos às famílias a nível nacional.

No terceiro grupo, países com lacunas severas de proteção, percebe-se que as transferências de renda foram pontuais e como um bônus adicional em uma ou poucas cotas, mesmo para os beneficiários dos programas existentes anteriormente.

A Bolívia concedeu para os beneficiários do Bono Família uma transferência adicional única de 500 bolivianos (72 dólares) a partir de março de 2020 e esta foi estendida em abril para alunos com deficiência e alunos que frequentavam escolas particulares e de educação especial. Também em abril, foi concedida a transferência de 500 bolivianos (72 dólares) a todos os bolivianos com idades entre 18 e 60 anos que não eram beneficiários de outros programas públicos de transferência de dinheiro.

O bônus anual dos beneficiários do programa Renta Dignidad foi pago antecipadamente, em julho de 2020. Também uma transferência de 1.000 bolivianos, 143 dólares, (Bono contra el Hambre) foi atribuída a todos os adultos bolivianos que estavam desempregados e eram beneficiários de programas selecionados de transferência de dinheiro existentes. Uma cesta de alimentos foi concedida a famílias de baixa renda em março de 2020. Já o governo do Paraguai liberou em março um subsídio de $25 \%$ do 
salário-mínimo por dois meses para trabalhadores informais. Para os trabalhadores com carteira assinada, foi liberado um subsídio temporário para licença médica ou suspensão de contratos. Também foi feita, em março, uma transferência de dinheiro através de um bônus para beneficiários, enviado como código aos celulares, e com o qual podiam ser adquiridos alimentos e produtos de higiene. Em abril de 2020, foi possibilitada a antecipação do pagamento da pensão para os idosos em situação de pobreza. Em maio de 2020, foi feito um pagamento adicional aos beneficiários do Programa de Transferência de Renda - Tekoporã, equivalente a 50\% do valor do repasse bimestral normal.

Em agosto de 2020, foi realizada uma única transferência emergencial de renda Gs.500.000 (73 dólares) para populações vulneráveis de 22 distritos do departamento de Alto Paraná. E foi criado um subsídio de emergência sanitária, o Pytyvõ 2.0, que fez dois pagamentos para os trabalhadores informais em alguns setores da economia, priorizando os trabalhadores que residem em cidades fronteiriças entre agosto e outubro.

Em relação à garantia de alimentação, foram entregues alimentos para organizações comunitárias responsáveis pelas cozinhas populares em março e junho de 2020. E foram distribuídos kits de alimentação aos alunos em substituição ao Programa de Alimentação Escolar del Paraguay em final março de 2020, além de kits de alimentos não perecíveis para famílias de artesãos indígenas em abril de 2020.

O desenho das transferências guarda diferenças importantes entre os países, sendo muito distintos os critérios para identificação dos públicos. Alguns países, como o Chile, criaram bônus para indivíduos e para territórios, enquanto outros se concentraram em criar transferências relativas à inserção dos indivíduos no mercado de trabalho, como os trabalhadores informais na Argentina, Peru, Brasil, Chile, Paraguai e Uruguai. Outros programas não focaram nos trabalhadores do setor informal, mas selecionaram beneficiários dos auxílios emergenciais a partir de outros recortes, identificando população em situação de pobreza ainda não atendida pelos programas existentes, como é o caso da Bolívia ou do 
Equador. Todos os países realizaram ações voltadas para segurança alimentar, variando o público - para estudantes e/ou para população em geral - e a forma de provisão: em espécie ou em créditos para alimentação.

\section{Considerações finais}

Os estudos sobre proteção social na América Latina expressam uma agenda de pesquisa bem consolidada e que deve ser ainda mais estratégica em um contexto de pós-pandemia. O artigo buscou identificar, ainda que de forma exploratória, as ações de proteção social não contributiva desenvolvidas pelos países da América Latina para o enfrentamento dos efeitos da pandemia do COVID-19, para, a partir delas, discutir alguns desafios enfrentados na região. Têm-se que os países responderam rapidamente às exigências impostas pela crise sanitária e desenvolveram distintas modalidades de benefícios de transferência de renda. Portanto, percebe-se o esforço dos países com as medidas de emergência para o enfrentamento dos efeitos sociais da pandemia, com o comprometimento de recursos significativos. Importante destacar também a institucionalidade prévia construída pelos programas de transferência de renda e que foram importantes como medidas de proteção das famílias.

Das 30 iniciativas levantadas, 16 eram novas, sendo que as demais consistiram no aumento do valor e/ou na expansão de programas de transferência de renda já existentes. Pode-se identificar que não existe uma perspectiva de fundo que permita verificar, sem ambiguidades, as diferenças nos tipos das respostas dos países a partir de sua estrutura de proteção social, se esta é mais ou menos desenvolvida, com brechas maiores ou menores de proteção. Entretanto, pode-se perceber que, no grupo dos países com lacunas severas de proteção, como é o caso da Bolívia e do Paraguai, têm-se que as transferências de renda foram pontuais e muitas vezes foram realizadas como um bônus adicional em 
uma ou poucas cotas, mesmo para os beneficiários dos programas existentes anteriormente. Nos países com lacunas moderadas de proteção, percebe-se uma heterogeneidade de aproveitamento da rede existente no caso do Peru e uma ação muito tímida do Equador. Nos países com lacunas menores de proteção, percebe-se um aproveitamento das políticas existentes e, mesmo que ocorram mudanças políticas com sérias consequências para o sistema de proteção, como é o caso do governo brasileiro, o fato de ter uma rede constituída possibilitou um aporte maior de ação.

A natureza das ações desenvolvidas foi bastante similar dentre os países analisados, com variações de magnitude e desenho das transferências, mas sem que as diferenças nas brechas de proteção dos países possam explicar diferenças entre as ações desenvolvidas, já que estas foram muito similares. Para avaliar com clareza a efetividade das ações desenvolvidas e sua capacidade de proteção efetiva da população no contexto da crise pandêmica, seria necessário lançar mão de outros dados que aqui não serão considerados, como a cobertura da população, uma comparação entre os valores dos benefícios para identificar sua capacidade, de fato, de garantir manutenção das condições de vida da população, a incidência da doença, do isolamento social e dos efeitos produzidos em cada país analisado, o que extrapola os objetivos ou o alcance do presente artigo.

As ações levantadas no artigo tiveram como objetivo fornecer um panorama do que foi desenvolvido na América Latina e, com mais foco, em alguns países, para o enfrentamento dos efeitos socioeconômicos da pandemia no campo das políticas de transferência de renda, sobretudo. Um estudo sobre o impacto das diferentes medidas governamentais adotadas sobre o desempenho econômico de 45 países em 2020 evidenciou que os gastos públicos voltados para renda das famílias e de alívio das empresas foram fundamentais para evitar uma maior queda do PIB ou a deterioração mais ampla da economia. Logo, "[o]s resultados das nossas estimações indicam que aumentos de 1\% do gasto público em 
relação ao PIB promoveram um aumento do Índice semanal da atividade econômica da OCDE de entre 1,9 e 2,1\% em relação ao seu valor inicial (SANCHES, CARDOMINGO, CARVALHO, 2021, p. 2)."

Os países analisados expandiram os valores dos benefícios existentes para o público já atendido pelos programas de transferência de renda e também desenvolveram ações de transferência para grupos novos, para cobrir pessoas que trabalhavam no setor informal e que não faziam parte dos beneficiários dos programas de transferência de renda existentes. Dado o caráter sistêmico da crise sanitária, econômica e social que impõem novos desafios para os sistemas de proteção social para os países da região, soluções de transferência de renda são necessárias, mas não suficientes para enfrentar os danos da perda de emprego, da fragilidade dos vínculos trabalhistas e, consequentemente, com grande parte da população com uma precária inserção no mercado de trabalho, sendo esta uma marca das sociedades latino-americanas.

Os trabalhadores formais - e também os informais - encontram-se em situação de desproteção, o que gera pressão sobre as políticas não contributivas, que se encontram, por sua vez, ameaçadas em sua existência. Tem-se assim armada a tensão estrutural da proteção social para o conjunto da sociedade na América Latina. Combinar políticas de assistência social - das quais as transferências monetárias eventuais ou permanentes constituem apenas uma parte - com políticas de trabalho e renda, e ainda de forma articulada com as demais políticas sociais, como pretende o paradigma da proteção social com foco em direitos (CECCHINI; MARTINEZ, 2011), constitui o desafio das sociedades latino-americanas.

Os déficits de cobertura do sistema previdenciário público, associada às questões do grande mercado informal, da precarização do trabalho e do desemprego, aumentam e sobrecarregam o sistema assistencial não contributivo, como ficou evidente agora na Pandemia do COVID-19. O aparecimento da pandemia veio a agravar e evidenciar ainda mais suas fragilidades, mas também afirmar a centralidade do Estado para a prevenção de situações de risco e para mitigação e superação dos efeitos 
gerados pela ocorrência dos eventos que demandam proteção à população por parte do Estado. Tem-se, portanto, um elemento central de natureza macro e estrutural e que tem a ver com os impactos dos investimentos que o Estado faz na provisão da proteção social. Os déficits de proteção social existentes podem comprometer os planos de recuperação de cada país, expor milhões de pessoas à pobreza e à fome, ampliar os abismos das desigualdades e afetar a capacidade de reação global para enfrentar crises semelhantes no futuro.

O discurso ou a narrativa de austeridade fiscal, tão recorrente na história latino-americana, serve ao propósito de justificar a redução do Estado no que se refere à garantia dos direitos sociais e, principalmente, sua retração no campo da proteção social. O ponto, portanto, é esse: é no orçamento em que se expressam as intenções e orientações políticas, de modo que viabilizar os recursos necessários para efetivar direitos formalmente constituídos é tarefa precípua do Estado, com evidentes efeitos sociais e econômicos. E financiar esse investimento também é uma escolha política. Podemos alimentar esperanças de que a pandemia serviu para evidenciar, de uma vez por todas, o lugar único e absoluto das políticas de proteção social, que podem atuar de forma decisiva, para o bem ou para o mal, para a proteção ou não de suas populações, com impactos do ponto de vista do crescimento econômico (BRONZO, 2020). Nunca foi tão urgente e possível articular de forma sistêmica as políticas econômicas e as políticas sociais, compreendendo os efeitos econômicos do desenvolvimento social para além da defesa intransigente da democracia, que afinal só se materializa, substantivamente, se existe justiça social.

Essa é uma utopia, dadas as condições dos sistemas de proteção na região, que ainda padecem de sérios déficits de cobertura de serviços sociais básicos e que contam com sistemas recentes ou ainda incipientes de proteção social. A conquista da cidadania latino-americana passa pelo reconhecimento das amarras históricas e estruturais da desigualdade e da pobreza. Mas também por uma resposta ousada por parte dos governos, 
comprometidos com a criação de capacidades estatais necessárias para a provisão de políticas de proteção social, o que envolve estruturas robustas e estáveis de financiamento e capacidades técnicas para desenho e gestão de políticas públicas, além de capacidades políticas para legitimar a agenda de inclusão e estabelecer as estruturas de coordenação necessárias para uma adequada proteção social, que seja capaz de enfrentar as questões estruturais da produção e reprodução das desigualdades na América Latina.

\section{Referências}

ANDRENACCI, Luciano Enrique. Un ensayo sobre la historia de la ciudadanía en América Latina desde una perspectiva a largo plazo. Caderno. EBAPE.BR, v. 17, Edição Especial, Rio de Janeiro, nov. 2019. DOI: https://doi.org/10.1590/1679-395174321

ANTUNES, Ricardo. Uberização, trabalho digital e Indústria 4.0. São Paulo: Boitempo, 2020.

ARANHA, Adriana V. Estado em ação:ideias, atores e instituições no enfrentamento da fome e extrema pobreza no Brasil. Orientadora: Dra. Maria Rita Garcia Loureiro. 2019. 181 f. Tese de doutorado - Administração Pública e Governo. FGV EAESP - CDAPG, São Paulo, 2019. Disponível em: https://bibliotecadigital.fgv.br/dspace/bitstream/handle/10438/28785/TESE\% 20FINAL.AdrianaAranha.pdf?sequence=1\&isAllowed=y. Acesso em: 7 dez. 2021.

BOSCHETTI, Ivanete. A Seguridade Social na América Latina após o Dilúvio Neoliberal. Rio de Janeiro: Observatório da Cidadania , IBASE, v. 11, p. 91-98, 2007.

BRONZO, Carla. Entre pisar suavemente na terra ou comer suas entranhas: as escolhas que fazemos nos definem. Fórum DEMOCRACIA, POLÍTICAS PÚBLICAS \& COVID-19. Revista NAU Social - v.11, n.20, p. 81 - 89 maio/out $2020 . \quad$ Disponivel em: https://www.portalseer.ufba.br/index.php/nausocial/article/viewFile/36557/21 014. Acesso em: 20 dez. 2021

BRONZO, Carla; REPETTO, Fabián. Enfoque integral de la protección social y desafíos para América Latina. In: BRONZO, Carla; REPETTO, Fabián (orgs). Coordinación de políticas sociales: desafíos para la gestión pública. Estudio $n^{\circ} 18$ Serie: Análisis. EUROSOCIAL. Madri, 2015 Disponível em: 
http://sia.eurosocial-ii.eu/files/docs/1453800699-estudio_18.pd. Acesso em: 3 dez. 2021.

BUSSO, Matías; CAMACHO, Juanita; MESSINA, Julián; MONTENEGRO, Guadalupe. Social Protection and Informality in Latin America during the COVID-19 Pandemic. IDB Inter-American Development Bank. Working Paper Series. 1171. nov. 2020. DOI: http://dx.doi.org/10.18235/0002865

CASALI, Pablo; CETRÁNGOLO, Oscar; PINO, Ariel. OIT. Protección social en América Latina y el Caribe en tiempos de pandemia. Organización Internacional del Trabajo - OIT: Nota técnica regional. Panorama Laboral en tiempos de la COVID-129. oct. 2020. Disponível em: www.ilo.org/americas/publicaciones/WCMS_759164/lang--es/index.htm.

Acesso em: 3 dez. 2021.

CASTEL, Robert. As metamorfoses da questão social: uma crônica do salário. Petrópolis: Editora Vozes, 2010.

CECCHINI, Simone; MARTÍNEZ, Rodrigo. Protección social inclusiva en América Latina: una mirada integral, un enfoque de derechos. Santiago de Chile: Cepal/GIZ, 2011. Disponível em: http://hdl.handle.net/11362/2593. Acesso em: 3 dez. 2021.

CECCHINI, Simone, FILGUEIRA, Fernando; ROBLES, Claudia. Social Protection Systems in Latin America and the Caribbean. A comparative view. United Nations Publication. CEPAL. NoV. 2014. ISSN 1564-4162. Disponível em: http://hdl.handle.net/11362/37340. Acesso em: 3 dez. 2021.

CECCHINI, Simone; ATUESTA, Bernardo. Programas de transferencias condicionadas en América Latina y el Caribe: Tendencias de cobertura y inversión. Santiago del Chile: CEPAL, 2017. (Serie Políticas Sociales). Disponível em: http://hdl.handle.net/11362/41811. Acesso em: 3 dez. 2021.

CEPAL (Comisión Económica para América Latina y el Caribe). La prolongación de la crisis sanitaria y su impacto en la salud, la economía y el desarrollo social. Disponível em: https://www.cepal.org/es/publicaciones/47301-la-prolongacion-la-crisis-sanit aria-su-impacto-la-salud-la-economia-desarrollo. 2021a. Acesso: 3 dez. 2021.

CEPAL (Comisión Económica para América Latina y el Caribe). La paradoja de la recuperación en América Latina y el Caribe Crecimiento con persistentes problemas estructurales: desigualdad, pobreza, poca inversión y baja productividad. Informe Especial COVID-19. N.11. 2021b. Disponivel em: hdl.handle.net/11362/47043. Acesso em 20 dez. 2021.

CEPAL (Comisión Económica para América Latina y el Caribe). Panorama Social de América Latina - 2020. CEPAL, 2021c. Disponível em: https://www.cepal.org/es/publicaciones/46687-panorama-social-america-lat ina-2020. Acesso em: 3 dez. 2021. 
FILGUEIRA, Fernando. Tipos de welfare y reformas social en América Latina: Eficiencia, residualismo y ciudadanía estratificada. In: MELO, Marcus A. (org). Reforma do Estado e mudança institucional no Brasil. Recife: Editora Massangana, 1999, pp. 73-110.

LUSTIG, Nora. Desigualdade e descontentamento social na América Latina. Nueva Sociedad, dez. 2020. Disponível em: https://nuso.org/articulo/desigualdade-e-descontentamento-social-na-ame rica-latina/. Acesso em: 15 maio 2021.

MARSHALL, Theodor H. Cidadania e Classe Social. In: Cidadania, Classe Social e Status. Rio de Janeiro, Zahar Ed. 1967.

MESA-LAGO, Carmelo. El Desarrollo de la Seguridad Social en América Latina. Santiago: CEPAL, Estudios e Informes n 43, 1985.

MESA-LAGO, Carmelo. Las reformas de pensiones en América Latina y su impacto en los principios de la seguridad social, 2004. Santiago de Chile: CEPAL, Série Financiamiento del Desarrollo, vol. 144, mar. 2004. Disponível em: http://hdl.handle.net/11362/5126. Acesso em: 3 dez. 2021

PNUD (PROGRAMA DAS NAÇÕES UNIDAS PARA O DESENVOLVIMENTO). Relatório do Desenvolvimento Humano, 2019. Além do rendimento, além das médias, além do presente: Desigualdades no desenvolvimento humano no século XXI. Disponível em: http://hdr.undp.org/sites/default/files/hdr_2019_pt.pdf. Acesso em: 5 jul. 2021.

RACZYNSKI, Dagmar. La crisis de los viejos modelos de protección social en América Latina: nuevas alternativas para enfrentar la pobreza In. TOKMAN, $\mathrm{V}$. E.; O'DONELL, G (orgs) Pobreza y desigualdad en América Latina: temas y nuevos desafíos. Buenos Aires: Ed. Paidós, 1999

SANCHES, Marina; CARDOMINGO, Matias; CARVALHO, Laura. Quão mais fundo poderia ter sido esse poço? Analisando o efeito estabilizador do Auxílio Emergencial em 2020. Nota de Política Econômica $\mathrm{n}^{\circ} 007$. MADE/USP, 2021. Disponivel em: https://madeusp.com.br/publicacoes/artigos/quao-mais-fundo-poderia-ter-s ido-esse-poco-analisando-o-efeito-estabilizador-do-auxilio-emergencial-e $\mathrm{m}-2020 /$. Acesso em 03 dez. 2021

SUNDARARAJAN, Arun. Economia compartilhada: o fim do emprego e a ascensão do capitalismo de multidão. São Paulo: Senac São Paulo, 2019. 